\title{
Selection of Trusted Organic Food Sellers on Instagram Using Fuzzy Analytic Hierarchy Process
}

\author{
Ramona Ramli*1, Ahmad Zulqarnain Mohamed Ibrahim², Asmidar Abu Bakar ${ }^{3}$, Abdul Hadi Mohamad \\ 1,2,3 College of Computing and Informatics, Universiti Tenaga Nasional, 43000 Kajang, Selangor. \\ ${ }^{4}$ Malaysian Institute of Information Technology, Universiti Kuala Lumpur, 50250 Kuala Lumpur \\ ${ }^{4}$ College of Computing and Informatics, Saudi Electronic University, 13316 Riyadh \\ ${ }^{1}$ ramona@uniten.edu.my
}

Article History: Received: 10 November 2020; Revised: 12 January 2021; Accepted: 27 January 2021; Published online: 05 April 2021

\begin{abstract}
The awareness of a healthy lifestyle, particularly in food intake, has resulted in the visibility of organic food products. Most of the organic food products are local-based and home-grown. The popularity of Social Network Sites (SNSs) opens the opportunity for organic food sellers to educate, promote, and market their products to customers. However, the credibility of organic food sellers remains as barriers for customers to purchase from them. In this study, we investigate the organic food sellers selection problem, and the Fuzzy Analytic Hierarchy process method is applied to determine the most trusted sellers. Organic food sellers with the highest priority weight will be select as trusted sellers. The results of the study expected to be used by organic food sellers to improve their business operations. At the same time, the results will serve as guidelines for customers to evaluate the trustworthiness of organic food sellers.
\end{abstract}

Keywords: Fuzzy AHP, Organic Food, Social Network Sites, Instagram, Trust

\section{Introduction}

Current trends people are becoming more conscious on healthy food intake to achieve quality and healthy lifestyle. Their awareness on food product has been increased by ensuring they are consuming health-certified and labeled food products. This phenomenon has resulted in an increased demand for organic products. Organic food is natural food items that are free from artificial chemicals such as fertilizers, antibiotics, and genetically modified organisms (Liu, Pieniak, \& Verbeke, 2014). In Malaysia, organic food awareness has raised interest among consumers and businesses. Most of the organic products are home-grown and sold domestically (Somasundram, Razali, \& Santhirasegaram, 2016).

The evolution of social commerce from e-commerce has engaged millennials to spend more time on social media, including social shopping. Millennials who are adolescents and young adults exposed to the advertisement, promotions, and product reviews posted on Social Network Sites(SNSs)(Klassen et al., 2018). Social interactions that allow user interaction and user-generated content help consumers to increase their confidence in purchase decisions via recommendations, reviews, and also rating(Tariq, Wang, Tanveer, Akram, \& Akram, 2019). Businesses are taking advantage of social commerce as a platform for marketing and customer engagement activities to increase their visibility and broader market segment.

The food industry are recognized among the highest total amount spent by consumers on e-commerce for 2018(NapoleonCat, 2019). In addition, 73\% of consumers in Malaysia are the users of popular social media such as Facebook and Instagram (Leng, 2019) and (Hussain et al., 2017). The popularity of Instagram has resulted in increasing numbers of virtual stores created by businesses. The unique characteristics of Instagram, such as hashtags, mentions, location tags, repost, and biography space, have given advantages to businesses (Prasertsith, Penjira, \& Penjuree, 2015). Moreover, the visual display of Instagram provides opportunities to trigger consumers' emotions and influence their purchase intention. These features allow opportunities for organic food businesses to use Instagram for their visibility, increase awareness, and educate consumers on healthy food products.

Despite the growth and advantages of Instagram, trust remains as the main issue in online shopping via social commerce (Putri, 2015). The credibility of the businesses becomes a barrier for consumers to shop online since there is no guarantee about it. Studies (Che \& Cheung, 2017; Din, Ramli, \& Bakar, 2018, 2020; Hussain et al., 2017a; Prasertsith et al., 2015; Putri, 2015)have been conducted on identifying influence factors of consumers' purchase intention via Instagram. The identified factors provide valuable insights for businesses that use Instagram to engage with customers and boost their sales. However, there are no previous studies that show how the influence factors can be used to determine reliable sellers or vendors, particularly in organic foods. 
AHP and also its extension, which is Fuzzy AHP (FAHP), have been known in research to determine alternatives in making decisions. Studies have been conducted in determining consumers' preferences in purchase decision using AHP (Elahi, Muqtadir, Anam, \& Mustafiz, 2017; Flamy Pangkey, Joyce Lapian, \& Tumewu, 2016; Islam et al., 2018; Oblak, Pirc Barčić, Klarić, Kitek Kuzman, \& Grošelj, 2017; Pieter, Wattimena, \& Lamia, 2018; Wibowo \& Tielung, 2016). Yossini (2013) also used AHP to investigate on customer's preferences on organic vegetables in Indonesia. Results from the study served as guidelines for marketers, investors, and policymakers in marketing organic vegetables. Based on the researcher's observation, little studies are investigating customers' preferences on organic products, mainly using Fuzzy AHP as decisionmaking tools.

Therefore, the objectives of this study are (1) to determine the customers' preference for organic food sellers or vendors using Fuzzy AHP methods and (2) to identify which are the most influential criteria in selecting the preferred organic food seller. The results of this study will help organic food sellers better understand consumers' decision-making behavior.

\section{Application Of Fuzzy Ahp In Determining Trustable Organic Food Sellers}

\subsection{Identifying the main criteria and sub-criteria for organic food selection to design the hierarchical Fuzzy AHP structure}

The overall objective of the organic food seller selection problem is to identify which was the best organic food seller. A lot of criteria should be taken into account because majority of the sellers use SNSs, particularly Instagram, as their business platform. The criteria and sub-criteria have been identified in the previous study(Ramli, Bakar, \& Ismail, 2017), as shown in Table 1. For the alternatives, three local organic food sellers that produce healthy peanut butter chosen for alternatives in this study. The selection of sellers based on top healthy food sellers as results from hashtags searched on Instagram. In the previous studies, a list of criteria and sub-criteria that influence customers' trust towards online SNSs Sellers have been identified, as shown in Table 1 .

Table 1. Criteria and sub-criteria

\begin{tabular}{ll}
\hline Criteria & Sub-criteria \\
\hline E-WoM & Positive Valence \\
\cline { 2 - 2 } Social Commerce Concepts & Negative Valence \\
\cline { 2 - 2 } Information Quality & Recommendation \\
\cline { 2 - 2 } & Rating \\
\hline & Accuracy \\
\hline & Relevance \\
\hline & Completeness \\
\cline { 2 - 2 } & Understandability \\
\cline { 2 - 2 } & Format \\
\cline { 2 - 2 } & Transaction Safety \\
\hline Format \\
\hline People & Transaction Safety \\
\cline { 2 - 2 } & Reputation \\
\cline { 2 - 2 } & Propensity to Trust \\
\hline
\end{tabular}

After the main criteria, sub-criteria and alternatives were determined, the hierarchy of the organic food selection was structured. Figure 1 shows the structuring of the organic food seller selection problem in a hierarchy of four levels. The top-level of the hierarchy represents the goal of the problem, which is the selection of the best organic food sellers. The second level of the hierarchy grouped under four categories, which are EWoM, information quality, social commerce constructs, and people. At the third level, these main criteria were decomposed into various sub-criteria that may affect the seller's choice. Finally, the bottom level of the hierarchy represents the three alternative organic food sellers. 


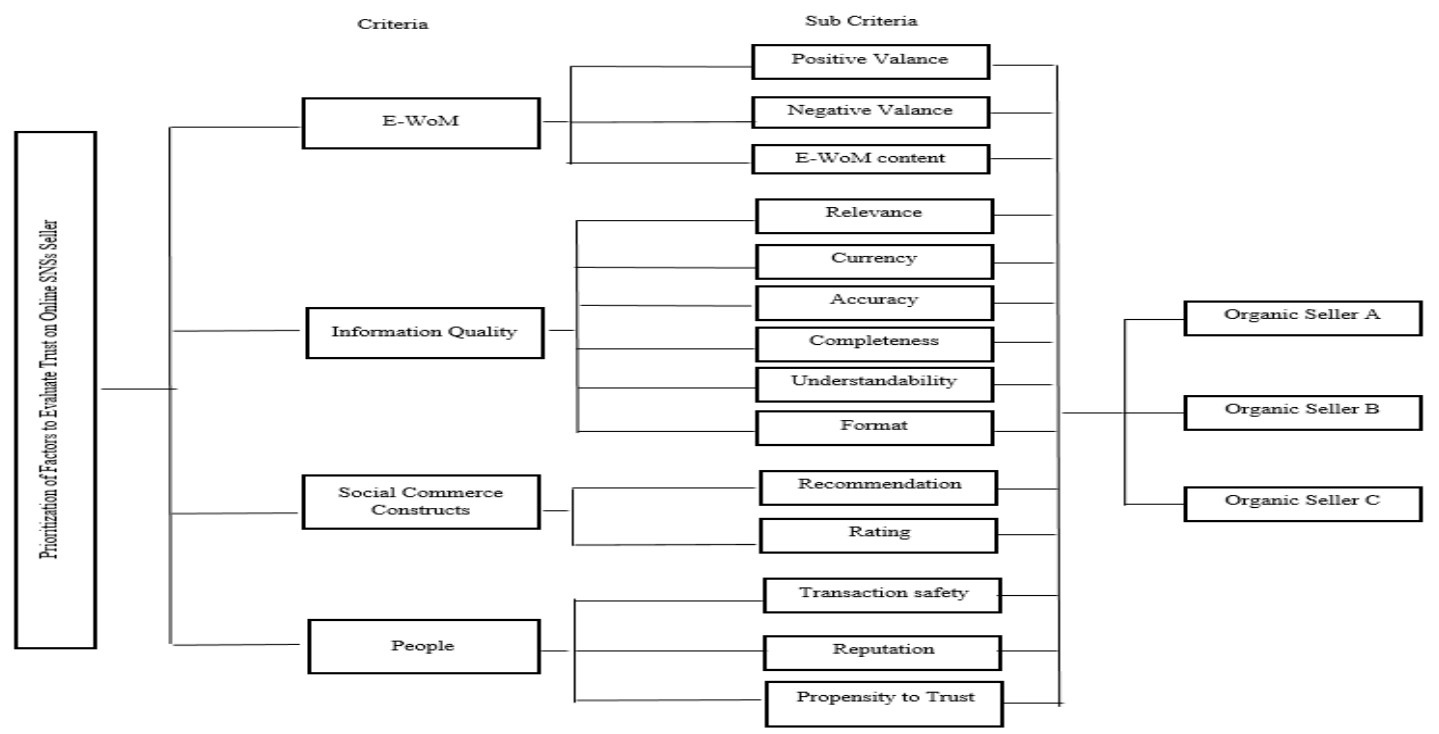

Figure 1. The hierarchy for organic food seller selection problem

\subsection{Pairwise comparison assessments}

In pairwise comparison, the importance of main criteria, sub-criteria and alternative over another were obtained through a questionnaire (Figure 2). The respondents are customers who active in online shopping with at least one transaction every three months. A total of 39 respondents were asked to evaluate the identified organic sellers based on their Instagram account. First, they compared the main criteria with respect to the main goal. Then, each sub-criteria were compared with the respect to the main criteria. Lastly, organic food sellers were compared with respect to the main criteria. Linguistic variables was used to make the pairwise comparisons which was then converted to fuzzy triangular numbers (Table 2)

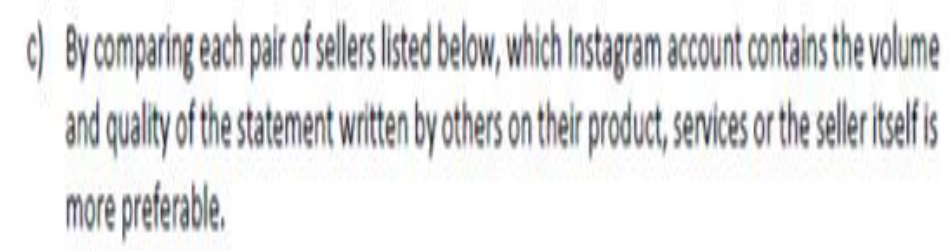

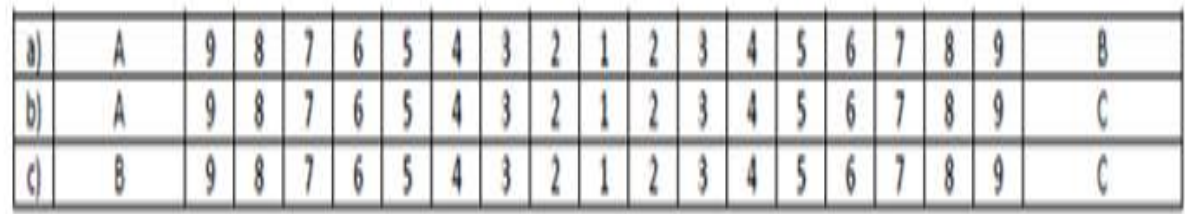

\begin{tabular}{|c|l|}
\hline Intensity of importance & Definition \\
\hline 1 & Equally importance \\
\hline 2 & Between equal and moderate importance \\
\hline 3 & Moderately importance \\
\hline 4 & Between moderate and strong importance \\
\hline 5 & Strongly importance \\
\hline 6 & Betwecenstrone and very strone importance \\
\hline 7 & Very strong importance \\
\hline 8 & Between very strong and extreme importance \\
\hline 9 & Extreme importance \\
\hline
\end{tabular}

Figure 2. Pairwise Comparison Questionnaire 
Table 2. Crisp to fuzzy conversion table

\begin{tabular}{lll}
\hline Saaty Scale & Definition & Fuzzy Trangular Scale (l,m,u) \\
\hline $\mathbf{1}$ & Equally importance & $(1,1,1)$ \\
\hline $\mathbf{2}$ & Between equal and moderate importance & $(1,2,3)$ \\
\hline $\mathbf{3}$ & Moderately importance & $(2,3,4)$ \\
\hline $\mathbf{4}$ & Between moderate and strong importance & $(3,4,5)$ \\
\hline $\mathbf{5}$ & Strongly importance & $(4,5,6)$ \\
\hline $\mathbf{6}$ & Between strong and very strong importance & $(5,6,7)$ \\
\hline $\mathbf{7}$ & Very strong importance & $(6,7,8)$ \\
\hline $\mathbf{9}$ & Between very strong and extreme importance & $(7,8,9)$ \\
\hline
\end{tabular}

\subsection{Develop fuzzy judgment matrix and aggregated fuzzy judgment matrix}

Results obtained from the questionnaire were translated into fuzzy triangular numbers, as presented in Table 2, since Fuzzy AHP uses linguistic values instead of crisp values. The judgment value from respondents were aggregated using geometric mean shown in equation (1) to develop the fuzzy judgment matrix.

$$
\left(u_{x}, m_{x}, l_{x}\right)=\left[\left(u_{1} * u_{2} * u_{3} \ldots * u_{n}\right)^{\frac{1}{n}},\left(m_{1} * m_{2} * m_{3} \ldots * m_{n}\right)^{\frac{1}{n}},\left(l_{1} * l_{2} * l_{3} \ldots * l_{n}\right)^{\frac{1}{n}}\right]
$$

After the aggregated fuzzy matrices were formed, the consistency of the pairwise judgment of each comparison matrix was checked using the calculation method of consistency index and consistency ratios in crisp AHP. For this purpose, each triangular fuzzy number, $\mathrm{M}=(\mathrm{l}, \mathrm{m}, \mathrm{u})$ in the pairwise comparison matrix was converted to a crisp number using equation (2).

$$
M_{\text {crisp }}=(4 \otimes m+l=u) / 6
$$

The consistency ratio of each comparison matrix was found to be under 0.10 . These results concluded that the consistency of the pairwise judgments in all matrices is acceptable. Table 3 shows the aggregated matrix for subcriteria positive valence with the calculated consistency ratio.

Table 3. Aggregated Fuzzy Judgment matrix for Positive Valence

\begin{tabular}{llll}
\hline Aggregated & $\mathbf{A}$ & $\mathbf{B}$ & $\mathbf{C}$ \\
\hline $\mathbf{A}$ & $(1.00,1.00,1.00)$ & $(0.95,1.13,1.42)$ & $(1.93,2.61,3.40)$ \\
\hline B & $(0.71,0.88,1.15)$ & $(1.00,1.00,1.00)$ & $(3.22,4.11,4.74)$ \\
\hline C & $(0.29,0.38,0.52)$ & $(0.20,0.24,0.30)$ & $(1.00,1.00,1.00)$ \\
\hline
\end{tabular}

Consistency ratio $=0.036$

\subsection{Determine priority weights of each criteria, sub-criteria and alternative}

In the next step, the priority weights of each main attribute, sub-attribute and alternative were calculated using FAHP method. As an example, the calculation of the priority weights of the sub-criteria is shown in Table 4. In order to derive the weights, the fuzzy synthetic extent values of the sub-criteria and were calculated based on the aggregated fuzzy judgment matrix. From the fuzzy synthetic extent values, the non-fuzzy values that represent the relative preferences or weights of one sub-criteria over other sub-criteria will be approximated. These relative weights were normalized to derive the final weights. From the table, we can conclude that the most important sub-criteria in the organic food selection process is recommendation because it has the highest priority weight. Transaction safety is the next preferred sub-criteria. The results also showed that seller A has the highest priority weight for each sub-criteria compared to other sellers. The next step is to select the most trusted organic food sellers.

\subsection{Compute the overall weight of each seller and choose the best seller}

The overall weights for alternatives were derived through composite prioritization. The composite priority weights of each alternative can be calculated by multiplying the weights of each alternative by the data of the corresponding sub-criteria. Sellers were ranked according to overall composite priority weights in the descending order. The results in Table 5 shows that seller $\mathrm{A}$ is the most trustable organic food seller with a weight value of $46.7 \%$; followed by seller B and seller $\mathrm{C}$ with a weight value of $36.1 \%$ and $17.2 \%$ respectively. 
Table 4. Sub-criteria priorities

\begin{tabular}{lllll}
\hline Sub Criteria & Seller A & Seller B & Seller C & Sub-criteria Priorities \\
\hline Positive Valence & 0.45 & 0.41 & 0.14 & 0.076 \\
\hline Negative Valence & 0.31 & 0.45 & 0.24 & 0.094 \\
\hline E-WoM Content & 0.52 & 0.34 & 0.14 & 0.074 \\
\hline Recommendation & 0.48 & 0.33 & 0.19 & 0.173 \\
\hline Rating & 0.40 & 0.33 & 0.19 & 0.098 \\
\hline Relevance & 0.43 & 0.41 & 0.15 & 0.027 \\
\hline Currency & 0.57 & 0.23 & 0.20 & 0.038 \\
\hline Accuracy & 0.55 & 0.31 & 0.14 & 0.041 \\
\hline Completeness & 0.53 & 0.32 & 0.15 & 0.033 \\
\hline Understandability & 0.48 & 0.37 & 0.15 & 0.037 \\
\hline Format & 0.44 & 0.39 & 0.17 & 0.030 \\
\hline Transaction Safety & 0.45 & 0.38 & 0.17 & 0.112 \\
\hline Reputation & 0.57 & 0.29 & 0.14 & 0.081 \\
\hline Propensity to Trust & 0.49 & 0.37 & 0.14 & 0.085 \\
\hline
\end{tabular}

Table 5. Ranking of alternatives

\begin{tabular}{llcc}
\hline Alternative & Composite Prioritization & Weight & Rank \\
\hline $\mathbf{A}$ & $(0.45 * 0.076)+(0.31 * 0.094)+(0.52 * 0.074)+(0.48 * 0.173)+(0.40 * 0.098)+(0.43 * 0.0$ & $46.7 \%$ & 1 \\
& $27)+(0.57 * 0.038)+(0.55 * 0.041)+(0.53 * 0.033)+$ & \\
& $(0.48 * 0.037)+(0.44 * 0.30)+(0.45 * 0.112)+(0.57 * 0.081)+(0.49 * 0.085)$ & \\
& $(0.41 * 0.076)+(0.45 * 0.094)+(0.34 * 0.074)+(0.33 * 0.173)+(0.39 * 0.098)+(0.41 * 0.0$ & $36.1 \%$ & 2 \\
& $27)+(0.23 * 0.038)+(0.31 * 0.041)+(0.32 * 0.033)+$ & \\
& $(0.37 * 0.037)+(0.39 * 0.030)+(0.38 * 0.112)+(0.29 * 0.081)+(0.37 * 0.085)$ & \\
\hline $\mathbf{C}$ & $(0.14 * 0.076)+(0.24 * 0.094)+(0.14 * 0.074)+(0.19 * 0.173)+(0.21 * 0.098)+(0.15 * 0.0$ & $17.2 \%$ \\
& $27)+(0.20 * 0.038)+(0.14 * 0.041)+(0.15 * 0.033)+$ & & \\
& $(0.15 * 0.037)+(0.17 * 0.030)+(0.17 * 0.112)+(0.14 * 0.081)+(0.14 * 0.085)$ & \\
\end{tabular}

\section{Conclusion}

In this study, a fuzzy AHP based approach was presented to select the trusted organic food sellers based on the identified criteria and sub-criteria. Four main criteria and 14 sub-criteria were identified based on the previous study conducted. Comparison of the main criteria, sub-criteria and sellers are made using a questionnaire. The weights of the main criteria, sub-criteria and alternatives were calculated using fuzzy AHP approach. The most trustable organic food seller was selected after computing the overall score of each seller. This study can be extended by integrating specific features of Instagram as a part of the criteria in selecting the trustable sellers. Also, The Fuzzy AHP calculation can incorporate into an expert system software. The integration may reduce the time spent by the customers in their purchase decision making. At the same time, the results provide organic food businesses with the focus areas they need to improve for their business competitiveness. The implementation of these improvements will increase the visibility of their product and gain more customers' trust in the future.

\section{Acknowledgment}

This research was funded by Universiti Tenaga Nasional, Malaysia, under the BOLD2025 Grant Scheme.

\section{References}

1. Che, J. W. S., \& Cheung, C. M. K. (2017). Consumer Purchase Decision in Instagram Stores : The Role of Consumer Trust. In Proceedings of the 50th Hawaii International Conference on System Sciences | (pp. 24-33).

2. Deliana, Y. (2013). Hierarchy of Consumer Decisions in Buying Organic Vegetables in Bandung. Res. J. Family, Community and Consumer Sci. International Science Congress Association, 1(7), $1-5$.

3. Din, S. M., Ramli, R., \& Bakar, A. A. (2018). A Review on Trust Factors Affecting purchase Intention on Instagram. In 2018 IEEE Conference on Application, Information and Network Security (AINS) (pp. 49-53). IEEE. 
4. Din, S. M., Ramli, R., \& Bakar, A. A. (2020). Developing and Validating an Instrument to Measure the Trust Effect Towards Instagram Sellers. In Lecture Notes in Electrical Engineering (Vol. 619, pp. 281-289). Springer.

5. Elahi, F., Muqtadir, A., Anam, S., \& Mustafiz, \&k. (2017). Pharmaceutical Product Selection: Application of AHP. International Journal of Business and Management, 12(8).

6. Flamy Pangkey, V., Joyce Lapian, S., \& Tumewu, F. (2016). The Analytical Hierarchy Process (Ahp) Of Consumer Purchase Decision In Selecting Bubble Tea Shop. The Analytical Hierarchy... Jurnal EMBA, 323(2), 323-331.

7. Hussain, A., Mkpojiogu, E.O.C., Almazini, H., Almazini, H. (2017). Assessing the usability of Shazam mobile app. AIP Conference Proceedings, 1891, art. no. 020057.

8. Hussain, A., Mkpojiogu, E.O.C., Jamaludin, N.H., Moh, S.T.L. (2017a). A usability evaluation of Lazada mobile application. AIP Conference Proceedings, 1891, art. no. 020059.

9. Islam, R., Abdul Ghani, A.B. (2018). Link among energy consumption, carbon dioxide emission, economic growth, population, poverty, and forest area evidence from ASEAN country. International Journal of Social Economics, 45 (2), pp. 275-285.

10. Klassen, K. M., Borleis, E. S., Brennan, L., Reid, M., McCaffrey, T. A., \& Lim, M. S. C. (2018). What people "like": Analysis of social media strategies used by food industry brands, lifestyle brands, and health promotion organizations on Facebook and Instagram. Journal of Medical Internet Research, 20(6).

11. Leng, L. K. (2019). Malaysians are the most active Instagram users in Asia Pacific | The Star Online. The Star.

12. Liu, R., Pieniak, Z., \& Verbeke, W. (2014). Food-related hazards in China: Consumers' perceptions of risk and trust in information sources. Food Control, 46, 291-298.

13. NapoleonCat. (2019). Instagram users in Malaysia.

14. Oblak, L., Pirc Barčić, A., Klarić, K., Kitek Kuzman, M., \& Grošelj, P. (2017). Evaluation of Factors in Buying Decision Process of Furniture Consumers by Applying AHP Method. Drvna Industrija, 68(1), 37-43.

15. Pieter, M. S. S., Wattimena, F. Y., \& Lamia, I. I. (2018). Decision Support System in giving recommendation for flat screen television purchase using Analytical Hierarchy Process (ahp) method. In Proceedings of the 2nd International Conference on Informatics and Computing, ICIC 2017 (Vol. 2018-January, pp. 1-5). Institute of Electrical and Electronics Engineers Inc.

16. Prasertsith, K., Penjira, K., \& Penjuree, K. (2015). The Factors Affecting Purchase Intention Of Fashion Accessories Through Instagram.

17. Putri, J. W. (2015). Factors Affecting Customers Online Search Intention and Online Purchase Intention using Social Networks : Case Study of Online Shop on Instagram. IBuss Management, 3(2), 232-240.

18. Ramli, R., Bakar, A. A., \& Ismail, R. (2017). The Trust Effect Towards Online Seller in Social Commerce. Proceedings of the 6th International Conference of Computing \& Informatics, (030), 317-322.

19. Somasundram, C., Razali, Z., \& Santhirasegaram, V. (2016, September). A review on organic food production in Malaysia. Horticulturae. MDPI Multidisciplinary Digital Publishing Institute.

20. Tariq, A., Wang, C., Tanveer, Y., Akram, U., \& Akram, Z. (2019). Organic food consumerism through social commerce in China. Asia Pacific Journal of Marketing and Logistics, 31(1), 202222.

21. Wibowo, S. W., \& Tielung, M. (2016). Analytical Hierarchy Process (Ahp) Approach On Consumer Preference In Franchise Fast Food Restaurant Selection In Manado City (Study at: McDonald's, KFC, and A\&W). M. Tielung. Analytical Hierarchy Process... Jurnal EMBA, 4(2), 22-028. 